\title{
Systematic Literature Review and Meta-Analysis of Sacral Neuromodulation (SNM) in Patients with Neurogenic Lower Urinary Tract Dysfunction (nLUTD): Over 20 Years' Experience and Future Directions
}

Arndt van Ophoven $\cdot$ Stefan Engelberg $\cdot$ Helen Lilley $\cdot$ Karl-Dietrich Sievert

Received: December 16, 2020 / Accepted: February 3, 2021 / Published online: March 13, 2021

(C) The Author(s) 2021

\section{ABSTRACT}

Introduction: Sacral neuromodulation (SNM) has been used in carefully selected patients with neurogenic lower urinary tract dysfunctions (nLUTD) for over two decades.

Methods: The aim of the current work was to perform a systematic literature review and meta-analysis of studies reporting the safety and

Supplementary Information The online version contains supplementary material available at https:// doi.org/10.1007/s12325-021-01650-9.

A. van Ophoven $(\varangle)$

Department of Neuro-Urology, Marien Hospital Herne, University Hospital Ruhr-Universität Bochum, Bochum, Germany

e-mail: arndt.vanophoven@marienhospital-

herne.de

S. Engelberg

Medtronic International, Tolochenaz, Switzerland

H. Lilley

PHMR Ltd., Berkeley Works, Berkley Grove, London, UK

K.-D. Sievert

Department of Urology, University Hospital OWL

Campus Lippe-Detmold, Detmold, Germany

K.-D. Sievert

Department of Urology, University Hospital

Tübingen, Tübingen, Germany

K.-D. Sievert

Department of Urology, Medical University Vienna,

Vienna, Austria effectiveness of SNM in patients with nLUTD (neurogenic detrusor overactivity, non-obstructive urinary retention, or a combination of both). For this purpose a systematic literature research was conducted using Embase (OvidSP), MEDLINE (OvidSP), MEDLINE In-Process Citations \& Daily Update (OvidSP), MEDLINE (OvidSP) e-Pub ahead of print, Cochrane Central Register of Controlled Trials (CENTRAL), NIH Clinicaltrials.gov, and WHO International Clinical Trials Registry Platform (ICTRP) between 1998 and March 2020, supplemented by a hand search.

Results: Forty-seven studies were included in the systematic literature review. Twenty-one studies comprising a total of 887 patients were included in the meta-analysis of test SNM. The pooled success rate of SNM test stimulation was $66.2 \%$ (95\% CI 56.9-74.4). Depending on neurogenic conditions test success rates varied greatly. Twenty-four studies with a total of 428 patients were included in the meta-analysis of permanent SNM. The success rate of pooled permanent SNM was $84.2 \%$ (95\% CI 77.8-89.0). Among the identified studies, the most common adverse events (AEs) were loss of effectiveness, infection, pain at implant site, and lead migration with $\mathrm{AE}$ rates of $4.7 \%, 3.6 \%$, $3.2 \%$, and $3.2 \%$, respectively. Limitations entail lower level of evidence (Oxford classification 3-4) of included studies, significant risk of bias, small sample sizes in some studies, the inclusion of retrospective case series, substantial 
between-study heterogeneity, heterogeneous patient populations, insufficient disease classification, and variations in terms of outcome parameters as well as techniques. Furthermore, long-term data are limited.

Conclusion: This meta-analysis supports not only the benefits of permanent SNM for various nLUTDs but also high overall success rates, similar to idiopathic patients. Current data of the analyzed studies showed that SNM is safe for these patients. However, more vigorous studies and/or registries are needed before definitive conclusions can be drawn.

Keywords: Implantable neurostimulators; Magnetic resonance imaging; Meta-analysis; Neurogenic lower urinary tract dysfunction; Sacral neuromodulation

\section{Key Summary Points}

Why carry out this study?

Sacral neuromodulation (SNM) has been used for more than 20 years in patients with neurogenic lower urinary tract dysfunctions (nLUTD).

With new MRI-safe devices available, there is an increasing interest in these indications. However, clinical data are limited.

\section{What was learned from the study?}

This systematic literature review supports the effectiveness and safety of SNM in patients with nLUTD.

More vigorous studies are needed.

\section{DIGITAL FEATURES}

This article is published with digital features, including a summary slide, to facilitate understanding of the article. To view digital features for this article go to https://doi.org/10.6084/ m9.figshare.13691674.

\section{INTRODUCTION}

With more than 325,000 implantations worldwide, sacral neuromodulation (SNM) has become a widely adopted treatment modality for non-neurogenic urge urinary incontinence (UUI), urgency-frequency syndrome, non-obstructive urinary retention, and fecal incontinence since its US Food and Drug Administration (FDA) approval in 1997, 1999, 1999, and 2011, respectively [1-5]. Although the pioneering preclinical and clinical research by Tanagho et al. on sacral nerve stimulation was based on neurological subjects [6], clinical evidence in this subpopulation is still limited.

Neurogenic lower urinary tract dysfunctions (nLUTD) comprise storage and voiding symptoms or a combination of both. These conditions can be subdivided into three categories: injury/trauma [i.e., spinal cord injury (SCI), cerebrovascular injury, pelvic surgeries], degenerative [i.e., multiple sclerosis (MS), Parkinson disease (PD)], and congenital (i.e., spina bifida, cerebral palsy). These neurologic patients show a wide spectrum of bladder pathologies depending on the level and extent of neuronal lesions. In addition, bladder symptoms may be accompanied by bowel or sexual dysfunctions [7]. The armamentarium of the bladder management encompasses anticholinergic drugs, beta-3-adrenergic receptor agonists, injections of botulinumtoxinA, intermittent catheterization, augmentation cystoplasty, and urinary diversion with a limited level of evidence for many of these treatment options in these oftendifficult-to-treat patients [8]. Since at least $40 \%$ of the neurologic patients are unsatisfied with their therapy regimen over the long term [9-11], there has been an intensive search for more therapeutic options.

In 2010, Kessler et al. reported promising results of SNM in patients with nLUTD: in a meta-analysis the pooled success rate for test SNM was $68 \%$ and the permanent SNM success rate was $92 \%$ [12].

In the current guidelines of the European Association of Urology (EAU) SNM has been described as a treatment for nLUTD, but without concrete guidance or recommendations 
[13]. The recently introduced new full-body magnetic resonance imaging (MRI)-safe SNM devices [14] will offer broader access to a patient group that has often been considered as a contraindication due to the need for regular MRI investigations. For example, in a populationbased study of patients with MS, prevalence rates of lower urinary tract symptoms or fecal incontinence were high, at $75 \%$ and $29 \%$, respectively [15]. With modern 3-T scanners widely available, MRI has become a commonly used tool for the evaluation of patients with MS, with many patients undergoing frequent MRI screenings for optimal therapeutic guidance $[16,17]$. Similarly, MRI is also used as surveillance in many patients with chronic SCI, which represents another group with a high prevalence of nLUTD $[18,19]$.

Since the meta-analysis by Kessler et al. many further studies have investigated SNM in nLUTD. This review aims to update the findings of the Kessler analysis and will address knowledge gaps in this challenging and often very heterogeneous patient population. A systematic literature search was conducted to collate effectiveness and safety evidence as primary and secondary outcome, and a meta-analysis was performed to determine the overall success rates of SNM test stimulation and chronic SNM with the permanent implant in the treatment of patients with nLUTD.

\section{METHODS}

\section{Data Sources and Searches for Systematic Literature Review}

The systematic literature review was conducted according to the Preferred Reporting Items for Systematic Reviews and Meta-Analyses (PRISMA) statement [20]. A search strategy was developed; the PICOS elements and search strings are provided in the supplementary material. The following databases were searched: Embase (OvidSP), MEDLINE (OvidSP), MEDLINE In-Process Citations and Daily Update (OvidSP), MEDLINE (OvidSP) e-Pub ahead of print, Cochrane Central Register of Controlled Trials (CENTRAL), NIH
Clinicaltrials.gov, and WHO International Clinical Trials Registry Platform (ICTRP). Electronic searches for identifying literature included a time period between January 1998 and March 31, 2020. The electronic searches were supplemented by a manual search. This article is based on previously conducted studies and does not contain any new studies with human participants or animals performed by any of the authors.

\section{Study Selection}

Inclusion and exclusion criteria of the systematic literature review are summarized in Table 1. Records retrieved during the searches were stored in a reference library and duplicate records were removed before screening (de-duplication). After de-duplication, every record retrieved in the search was marked as "include" or "exclude" after review of the study title and abstract (if available) by two independent reviewers. Full-text articles were obtained for citations that met the inclusion criteria or in cases in which it was unclear if the record met the inclusion criteria. The full-text review was also carried out by the two independent reviewers. Disagreements were resolved through discussion.

\section{Data Extraction and Quality Assessment}

The study variables recorded were year of publication, level of evidence, number of patients with nLUTD, sex, age, underlying neurological disorder, length of follow-up, and the success rates of test and permanent SNM. Criteria for success were based on the reviewer's judgment. Treatment success was generally defined as $\geq 50 \%$ improvement of symptoms, including other cutoff thresholds such as $\geq 70 \%, \geq 75 \%$ improvement, and cure, but other parameters such as significant symptom improvement, positive treatment outcome, patient satisfaction, non-failures, non-explants, or non-dropouts have also been used (see Table $2 S$ in the supplementary material).

Percentage and type of adverse events (AEs) were analyzed to assess safety. AEs were assigned 
Table 1 Systematic literature review: inclusion and exclusion criteria

\begin{tabular}{|c|c|}
\hline Inclusion criteria & Exclusion criteria \\
\hline $\begin{array}{l}\text { Patients treated with sacral } \\
\text { neuromodulation }{ }^{\mathrm{a}} \text { AND } \\
\text { nLUTD }\end{array}$ & $\begin{array}{l}\text { Conference abstracts } \\
\text { and systematic } \\
\text { reviews }\end{array}$ \\
\hline $\begin{array}{l}\text { LUTD was classified as } \\
\text { neurogenic according to the } \\
\text { author's judgments }\end{array}$ & $\begin{array}{l}\text { Studies not published as } \\
\text { full-text articles }\end{array}$ \\
\hline $\begin{array}{l}\text { nLUTD included the following } \\
\text { conditions, but were not } \\
\text { limited to: }\end{array}$ & Non-human studies \\
\hline Multiple sclerosis & Non-original articles \\
\hline Spinal cord injury & $\begin{array}{l}\text { Studies not published in } \\
\text { English }\end{array}$ \\
\hline $\begin{array}{l}\text { Cerebral vascular disease/ } \\
\text { cerebrovascular accident/ } \\
\text { cerebral palsy }\end{array}$ & $\begin{array}{l}\text { Patient populations } \\
\text { with age }<16 \text { years }\end{array}$ \\
\hline CNS tumor, CNS surgery & $\begin{array}{l}\text { Other therapies than } \\
\text { SNM/SNS }\end{array}$ \\
\hline \multicolumn{2}{|l|}{$\begin{array}{l}\text { Pelvic surgery (i.e., } \\
\text { hysterectomy, Wertheim) }\end{array}$} \\
\hline \multicolumn{2}{|l|}{ Parkinson disease } \\
\hline \multicolumn{2}{|l|}{ Back surgery/disc prolapse } \\
\hline \multicolumn{2}{|l|}{$\begin{array}{l}\text { Diabetic neuropathy, other } \\
\text { types of neuropathy }\end{array}$} \\
\hline \multicolumn{2}{|l|}{ Alzheimer's disease } \\
\hline \multicolumn{2}{|l|}{$\begin{array}{l}\text { Spina bifida/myelomeningocele } \\
\text { (MMC) }\end{array}$} \\
\hline \multicolumn{2}{|l|}{$\begin{array}{l}\text { Other: ependymoma, myelitis, } \\
\text { borreliosis, Dandy-Walker } \\
\text { syndrome, inflammatory } \\
\text { neuronal reaction, etc. }\end{array}$} \\
\hline \multicolumn{2}{|l|}{ Detrusor hyperreflexia } \\
\hline \multicolumn{2}{|l|}{ Detrusor sphincter dyssynergia } \\
\hline $\begin{array}{l}\text { Urinary retention, voiding } \\
\text { dysfunction }\end{array}$ & \\
\hline
\end{tabular}

Table 1 continued

\begin{tabular}{l}
\hline Inclusion criteria \\
\hline $\begin{array}{l}\text { Studies with at least one } \\
\text { relevant outcome reported }\end{array}$ \\
a Sacral neuromodulation (SNM), sacral nerve stimulation \\
(SNS)
\end{tabular}

to one of the following categories: infection, pain at implant, adverse stimulation, lead migration, lead breakage, hardware issues, adverse change in bowel function, loss of effectiveness, and other. Battery replacements were not considered a therapy revision or failure if due to battery depletion [21].

Quality appraisal of the included studies was carried out through classification of the level of evidence and type of study according to the Oxford Centre for Evidence-Based Medicine criteria reported by Howick et al. [22]. Furthermore, the methodological quality of the nonrandomized studies included in the meta-analysis was assessed using the ROBINS-I tool [23]. Risk of bias due to confounding factors, selection of participants, classification of interventions, deviations from interventions, missing data, measurement of outcomes, and selection of reported results was determined. Risk of bias graphs were generated by the online robvis tool [24].

\section{Data Synthesis and Analysis}

For this meta-analysis studies with at least four patients were included. Meta-analyses were conducted to generate pooled estimates for test and permanent success rates. Sensitivity analyses were conducted to assess the impact of including very small studies ( $\geq 4$ patients) versus larger studies ( $\geq 10$ patients) in the analyses. The pooled success rate estimates and corresponding 95\% confidence intervals were calculated using the DerSimonian-Laird randomeffects model to account for between-study heterogeneity. The analyses were conducted in 


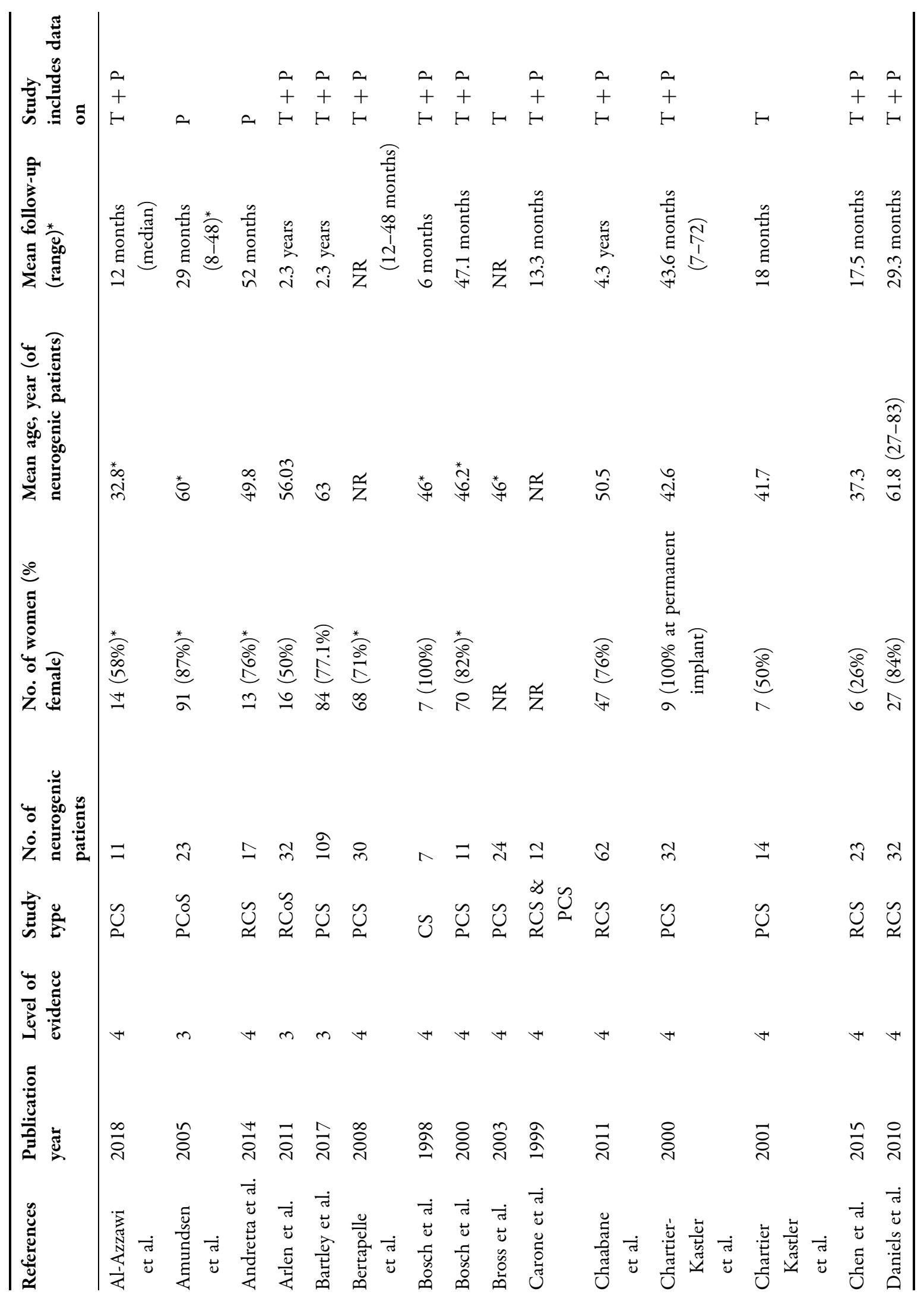




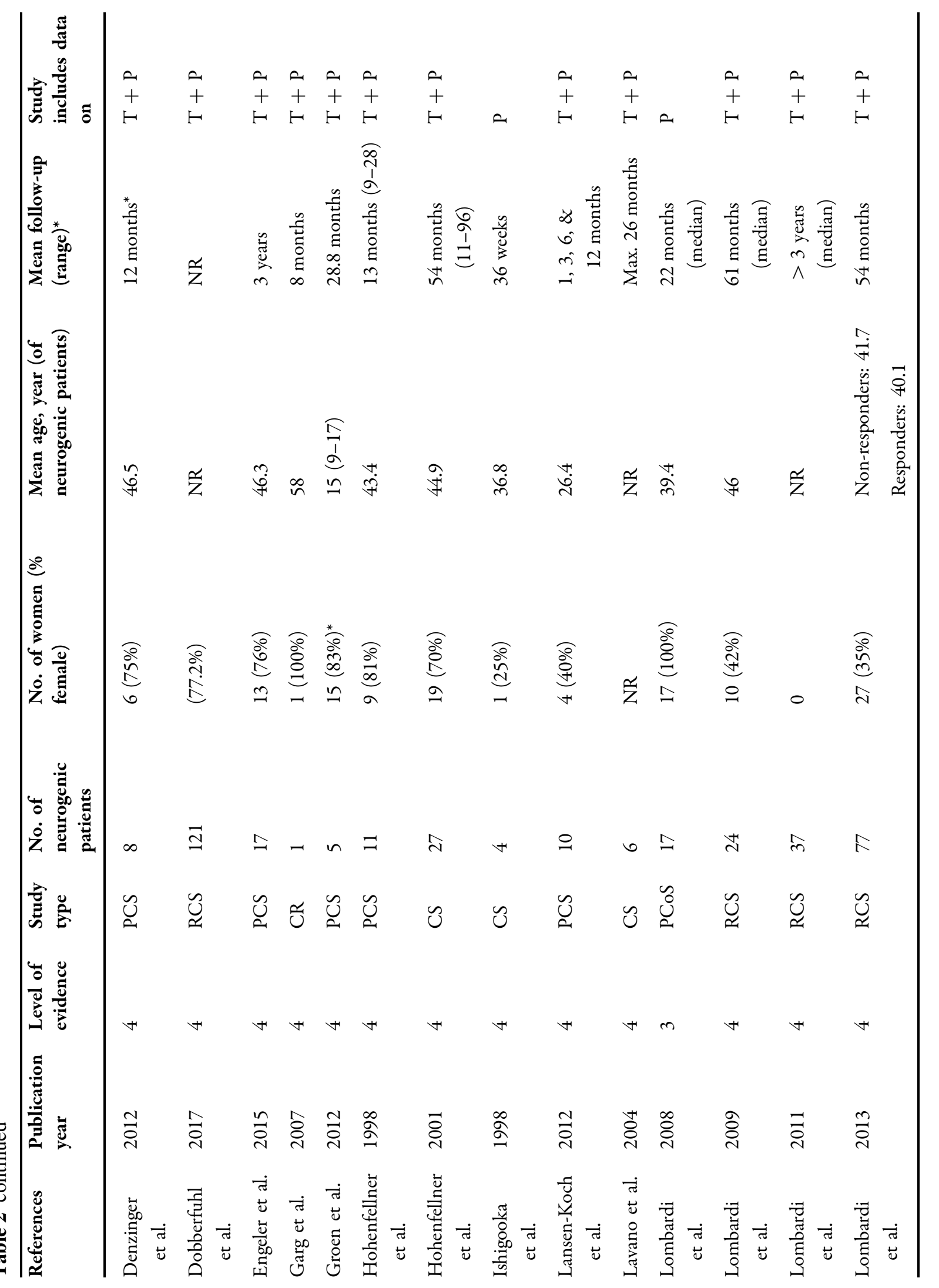




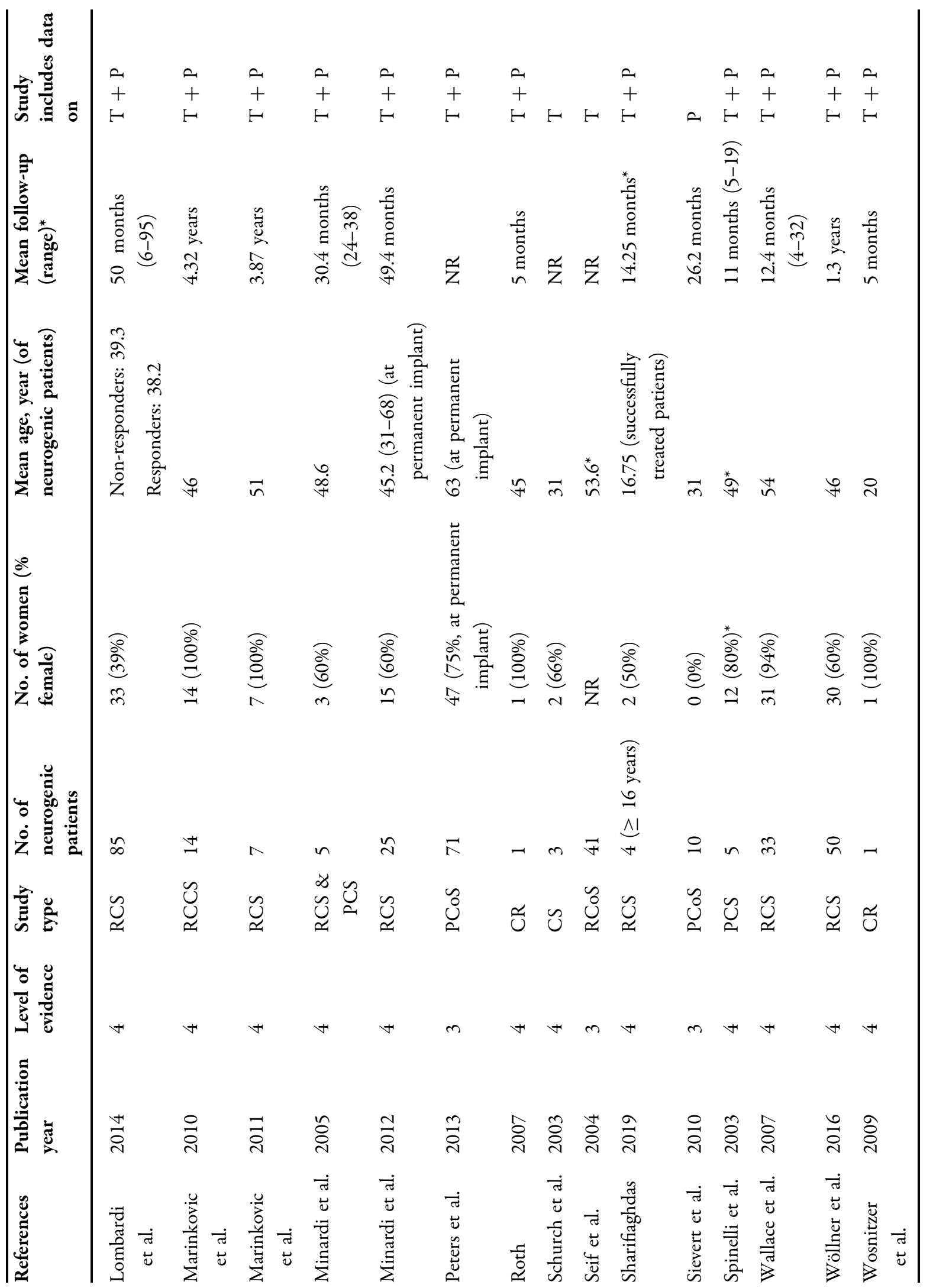




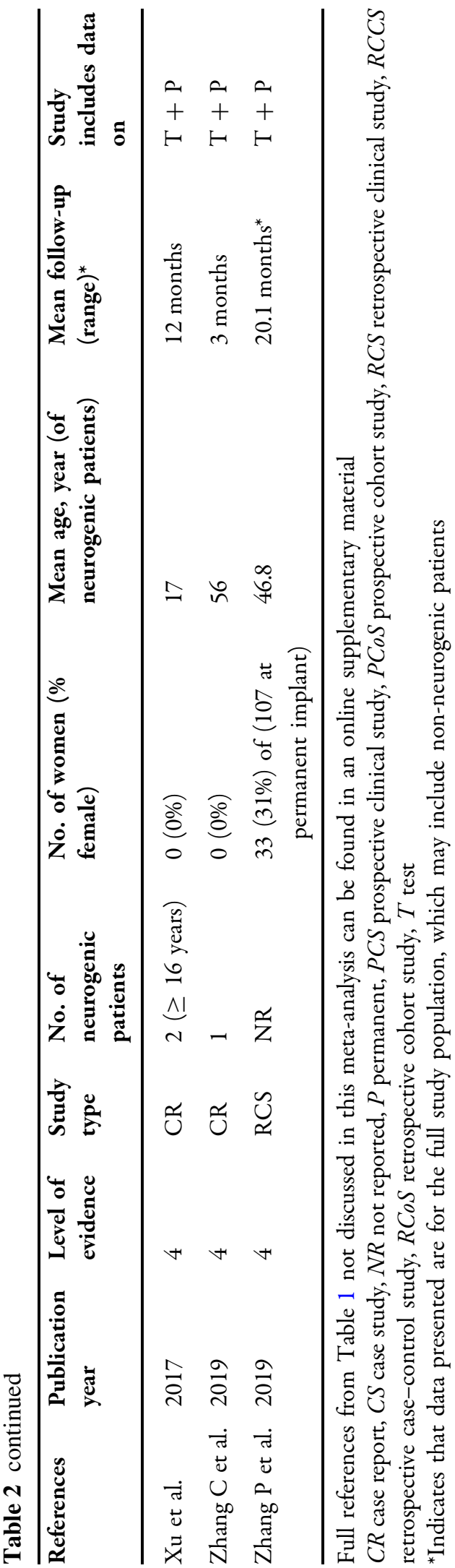

$\mathrm{R}$ version 3.5.3 (R Foundation for Statistical Computing, Vienna, Austria; 2019) [25] and used a logit transformation and inverse variance weighting.

\section{Search Results}

The search of the electronic databases retrieved 1522 records and 4 by additional hand search. This total was reduced to 1177 after de-duplication. A total of 993 records were excluded, leaving 184 records for a full review. Studies that only included children (aged $<16$ years) were excluded, as were non-human studies, non-original or non-English articles, studies not published as full-text articles or published before 1998 or later than March 31, 2020. In addition, studies without any relevant outcome parameter in the neurologic patient population were excluded. As the assumptions of a metaanalysis require studies to be independent (i.e., no overlap of patients), the most recent or relevant study was selected for inclusion in the analysis to avoid an overlap of patients.

\section{RESULTS}

\section{Included Studies}

A total of 47 records were identified for inclusion in the systematic literature review (Table 2). The level of evidence ranged from 3 to 4 according to the Oxford Centre for EvidenceBased Medicine [22]. Risk of bias graphs are presented in Figs. 1, 2. A flow diagram of the included/excluded records at each stage is shown in Fig. 3.

\section{Study and Patient Characteristics}

The identified studies included retrospective or prospective clinical studies, cohort studies, and case reports. Two studies (Carone et al. 1999; Minardi et al. 2005) [26, 27] were both a prospective and retrospective clinical trial. The level of evidence of all included studies was 3 or 4 according to the Oxford level of evidence table of 2011. In total 887 patients presenting 


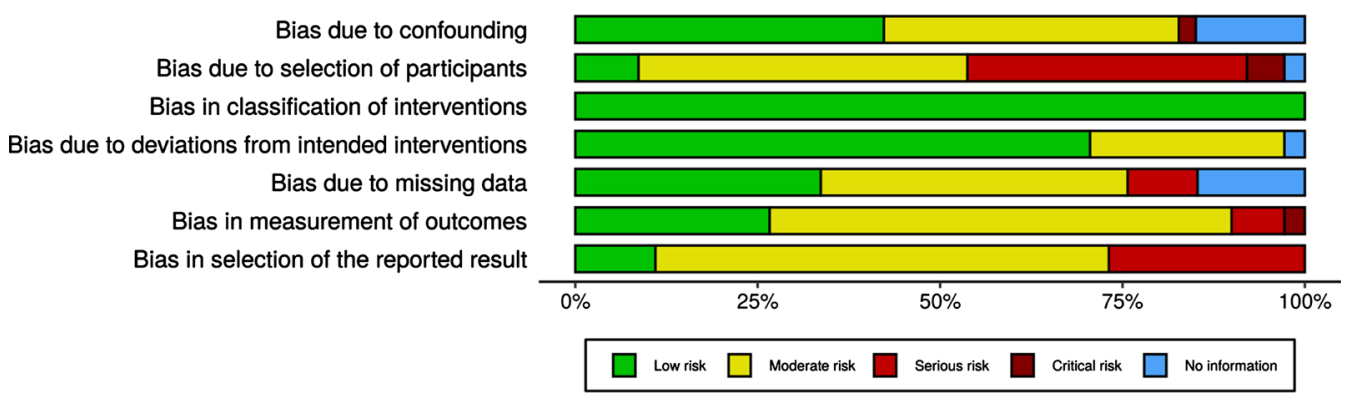

Fig. 1 Summary of the risk of bias of the studies included in the meta-analysis of permanent SNM. Results are weighted by sample size

with nLUTD across all included studies were identified. The mean patient age of the analyzed patient population ranged from 16.75 to 63 years (mean \pm standard deviation (SD), $47.7 \pm 12.6$ years) and the proportion of women in the analyzed, purely neurological patient population was $59.9 \%$. Most of the studies (38/47) reported both test and permanent SNM outcomes.

\section{Effectiveness of SNM}

\section{Test Success Rates by Underlying Condition}

The neurogenic conditions underlying LUTD in patients in the included studies are shown in Table 3 for the test stimulation. The conditions were reported for varying degrees of thoroughness. For example, the proportion of patients with a particular condition is not clearly stated in all studies, nor is the number of patients with a particular condition who successfully responded to the therapy. The imprecise nature of the reporting makes it difficult to estimate precise success rates of SNM in individual conditions. Moreover, there was a significant variation in the classification of the underlying conditions in the included studies.

The underlying conditions affecting most patients were back surgery, incomplete SCI, and MS, with at least 151, 116, and 94 patients undergoing test SNM, respectively. Test success rates for back surgery and MS were significantly higher than those for incomplete SCI $(84.1 \%$ and $76.6 \%$ versus $48.3 \%$ ). Lower test success rates of about $50 \%$ were also observed in patients with spina bifida/myelomeningocele, cerebral vascular disease, and PD, although the patient numbers in the last group was small $(n=11)$.

Complete SCI has long been considered a contraindication for SNM [28], since pioneering studies in this patient group failed to demonstrate any clinical benefit $[29,30]$. In contrast, early treatment with bilateral SNM during the spinal shock phase has shown promising results with 8 out of 10 patients benefiting from SNM [31].

\section{Test Success Rates by Type of nLUTD}

Dividing nLUTD in the three subgroups (neurogenic detrusor overactivity (nDO), neurogenic non-obstructive urinary retention, or a combination of both) revealed test success rates of $61 \%, 52 \%$, and $69 \%$, respectively.

\section{Meta-Analysis}

Twenty-one studies comprising a total of 887 patients were included in the meta-analysis of test SNM and the pooled test SNM success rate was $\quad 66.2 \% \quad(95 \% \quad$ CI $56.9-74.4) \quad$ (Fig. 4a) $[21,29,32-50]$. Twenty-four studies with a total of 428 patients were included in the metaanalysis of permanent SNM [21, 26, 29, 31-38, 40, 42-45, 48, 49, 51-56]. The success rate of pooled permanent SNM was 84.2\% (95\% CI 77.8-89.0) according to a perprotocol analysis (Fig. 4b). The likelihood of receiving a permanent, definitive SNM device is approximately $\quad 55 \% \quad$ (intention-to-treat analysis).

Sensitivity analyses were performed excluding studies with fewer than 10 patients in order 


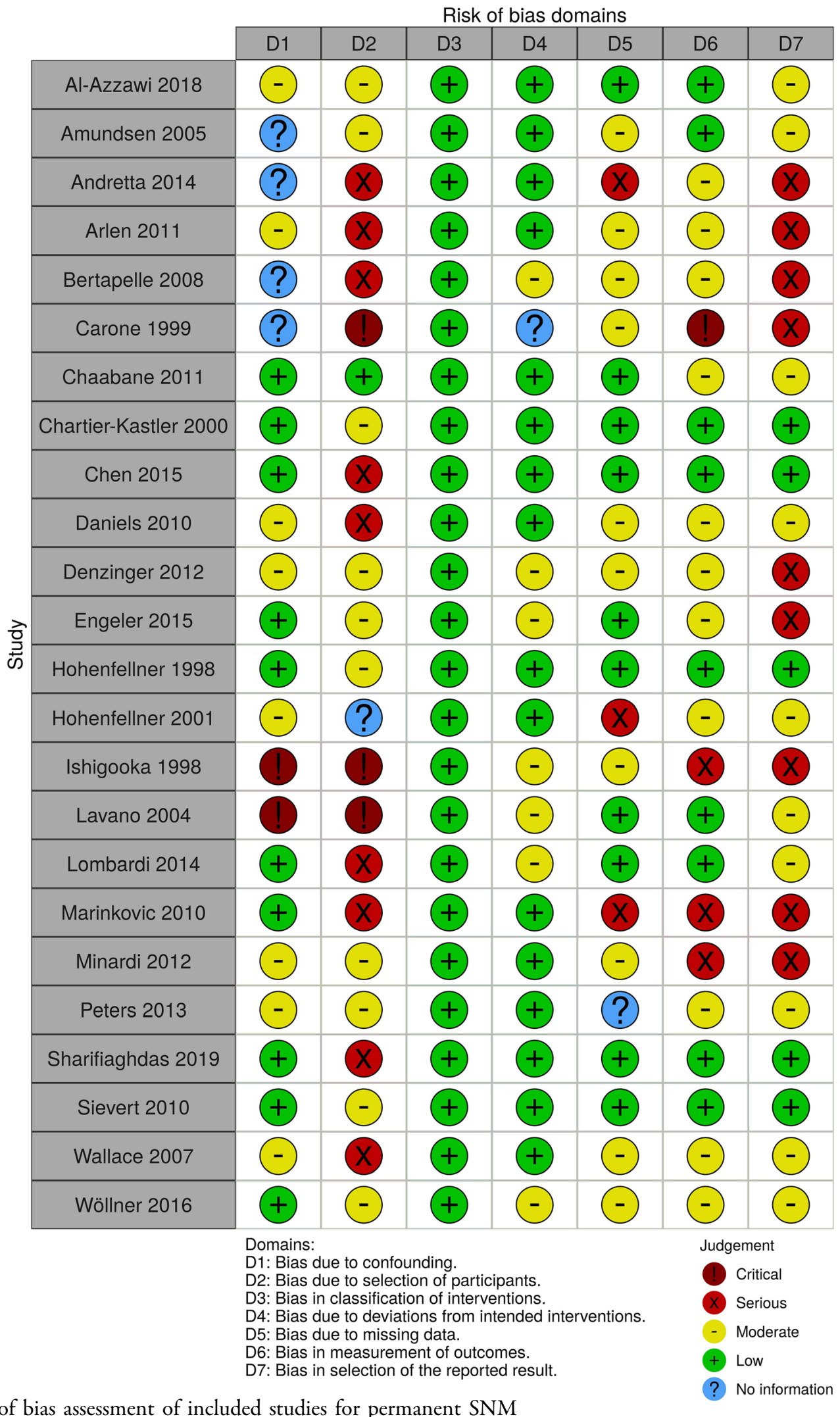

4Fig. 2 Risk of bias assessment of included studies for permanent SNM 
to assess the sensitivity of the results when including very small sample sizes (online supplementary material). The pooled success rates for test SNM and permanent SNM were 64.2\% (95\% CI 54.6, 72.8) and $82.9 \%$ (95\% CI 75.8, $88.2)$, respectively. Therefore, the results were comparable to the analyses including at least four patients.

\section{Safety of SNM (Chronic Implant)}

Following permanent SNM, AEs were reported by less than $25 \%$ of 494 patients with nLUTD. For comparison, Kessler et al. reported a similar pooled $\mathrm{AE}$ rate $(24 \%)$ in their meta-analysis from 2010 [12]. The results presented in Table 4 only include patients from studies in which AEs were reported, or in which it was specifically stated that no AEs occurred. The most common AEs were loss of effectiveness, infection, pain at implant site and lead migration with AE rates of $4.7 \%, 3.6 \%, 3.2 \%$ and $3.2 \%$ respectively. Adverse stimulation was reported in $2.0 \%$ of patients.

\section{DISCUSSION}

SNM is an established treatment modality for idiopathic (non-neurogenic) overactive bladder and non-obstructive urinary retention. However, its value for neurological patients seems to be less clear. In this meta-analysis of neurological patients pooled success rates for test SNM

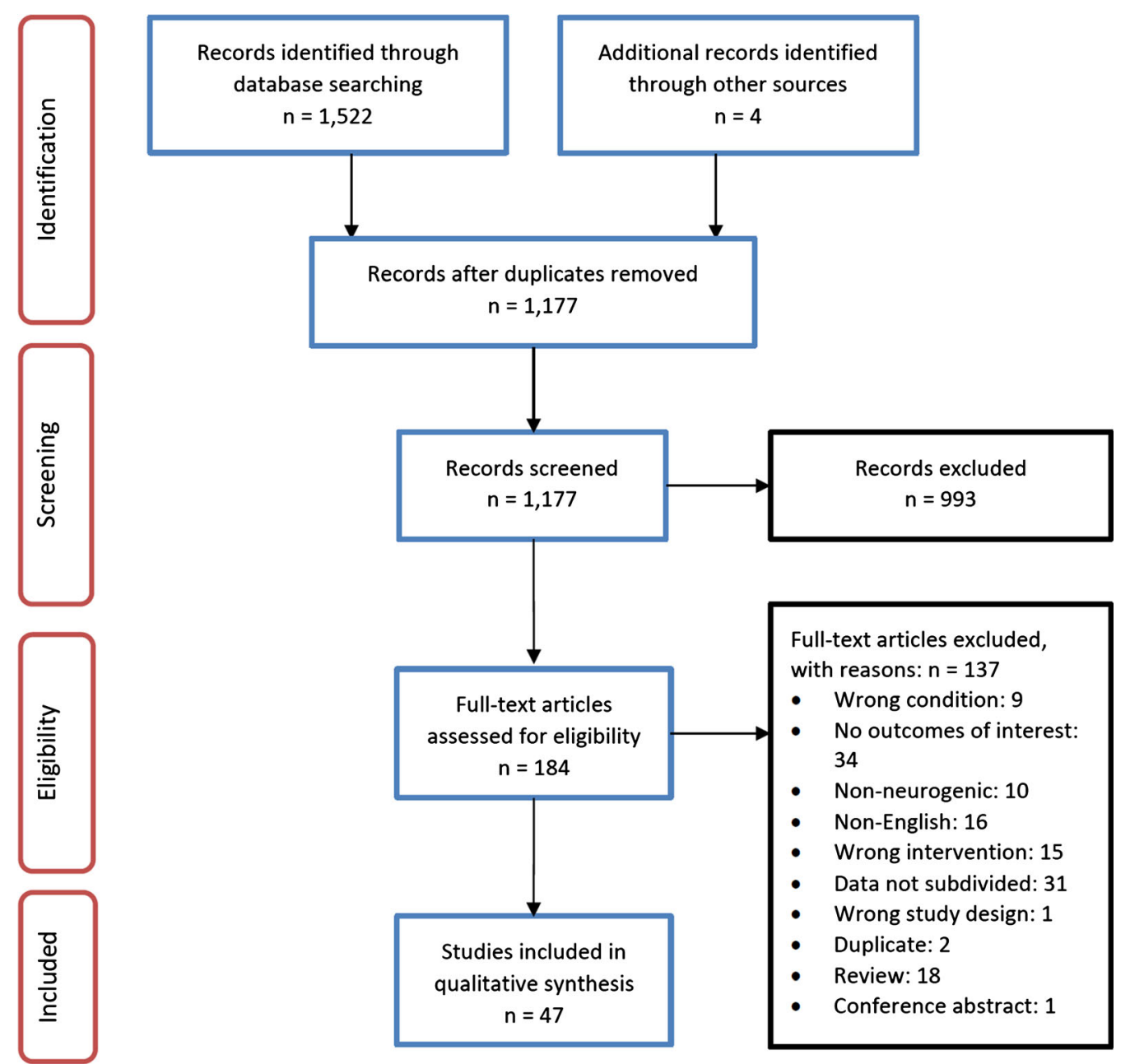

Fig. 3 PRISMA flow diagram of included/excluded studies 
(66.2\%) as well as for permanent SNM (84.2\%) seem to be comparable to SNM outcomes in idiopathic patient populations (test, $57-72 \%$ and $82 \%$ for permanent SNM) $[39,57]$. Likewise, in a prospective cohort study by Peters et al. comparing 71 neurogenic with 269 idiopathic patients it was concluded that the clinical benefits of SNM were equivalent for both groups [45]. The mean (SD) age of the neurological patient in this meta-analysis $(47.7 \pm 12.6$ years) is lower than in the typical idiopathic patient population (INSITE trial, $57.0 \pm 14.2$ years) [57]. The percentage of women in the purely neurological patient population was only $59.9 \%$ compared with $91 \%$ in the INSITE trial. AE rates were similar or even lower than those observed in the idiopathic population $[57,58]$. At a rate of $2.0 \%$ adverse stimulation was a relatively rare $\mathrm{AE}$ in comparison with the recent large INSITE study (22\%) [57].

Our meta-analysis, based on more than triple or double the patient sizes, respectively, are in line with Kessler et al. (2010) reporting a test success rate of $68 \%$ (256 patients) and a permanent success rate of $92 \%$ (206 patients) [12]. Since 2010 six prospective studies have been published that further strengthen Kessler et al.'s conclusions [32, 38, 40, 41, 45, 59]. For the majority of neurological patients, clinical

Table 3 Success rate of test SNM by underlying dysfunction

\begin{tabular}{|c|c|c|c|c|}
\hline Dysfunction & $\begin{array}{l}\text { Total no. of patients with } \\
\text { dysfunction }\end{array}$ & $\begin{array}{l}\text { No. of patients with } \\
\text { successful testing }\end{array}$ & $\begin{array}{l}\text { Success } \\
\text { rate }(\%)\end{array}$ & $\begin{array}{l}\text { Exact } 95 \% \text { confidence } \\
\text { interval }^{c}\end{array}$ \\
\hline Incomplete SCI & 116 & 56 & 48.3 & $(38.9 \%, 57.7 \%)$ \\
\hline Multiple sclerosis & 94 & 72 & 76.6 & $(66.7 \%, 84.7 \%)$ \\
\hline Back surgery $^{a}$ & 151 & 127 & 84.1 & $(77.3 \%, 89.5 \%)$ \\
\hline $\begin{array}{l}\text { Diabetes/ } \\
\text { polyneuropathy }\end{array}$ & 47 & 31 & 66.0 & $(50.7 \%, 79.1 \%)$ \\
\hline Spina bifida/MMC & 25 & 12 & 48.0 & $(27.8 \%, 68.7 \%)$ \\
\hline $\begin{array}{l}\text { Cerebral vascular } \\
\text { disease }\end{array}$ & 8 & 4 & 50.0 & $(15.7 \%, 84.3 \%)$ \\
\hline Parkinson disease & 11 & 6 & 54.5 & $(23.4 \%, 83.3 \%)$ \\
\hline Pelvic surgery & 9 & 7 & 77.8 & $(40.0 \%, 97.2 \%)$ \\
\hline Complete SCI & 9 & 0 & 0.0 & $(-,-)$ \\
\hline $\begin{array}{l}\text { Complete SCI (early } \\
\text { stim.) }\end{array}$ & 10 & 8 & 80.0 & $(44.4 \%, 97.5 \%)$ \\
\hline Cerebral palsy & 3 & 3 & 100.0 & $(-,-)$ \\
\hline $\begin{array}{l}\text { Other neurological } \\
\text { condition }\end{array}$ & 15 & 13 & 86.7 & \\
\hline Not clearly reported & 239 & 145 & 60.7 & \\
\hline Total & 737 & 484 & & \\
\hline
\end{tabular}


A

Study

Al-Azzawi et al. 2018

Arlen et al. 2011

Chaabane et al. 2011

Chartier-Kastler et al. 2000

Chen et al. 2015

Daniels et al. 2010

Denzinger et al. 2012

Dobberfuhl et al. 2018

Engeler et al. 2015

Hohenfellner et al. 2001

Lansen-Koch et al. 2012

Lavano et al. 2004

Lombardi et al. 2014

Marinkovic et al. 2010

Minardi et al. 2012

Peters et al. 2013

Seif et al. 2004

Spinelli et al. 2003

Wallace et al. 2007

Wöllner et al. 2016

Zhang $P$ et al. 2019

Random effects model

Heterogeneity: $I^{2}=83 \%, \tau^{2}=0.6145, \rho<0.01$
Events $\quad 95 \%-\mathrm{Cl}$

$36.36 \quad[10.93 ; 69.21]$

$62.50 \quad[43.69 ; 78.90]$

$66.13[52.99 ; 77.67]$

$28.12[13.75 ; 46.75]$

56.52 [34.49; 76.81]

$75.00 \quad[56.60 ; 88.54]$

$87.50 \quad[47.35 ; 99.68]$

66.94 [57.81; 75.22]

$94.12 \quad[71.31 ; 99.85]$

44.44 [25.48; 64.67]

$30.00 \quad[6.67 ; 65.25]$

100.00 [54.07; 100.00]

$42.35[31.70 ; 53.55]$

85.71 [57.19; 98.22]

60.00 [38.67; 78.87]

88.73 [79.00; 95.01]

65.85 [49.41; 79.92]

60.00 [14.66; 94.73]

84.85 [68.10;94.89]

$70.00 \quad[55.39 ; 82.14$

$58.79[51.27 ; 66.02]$

$66.18[56.86 ; 74.39]$

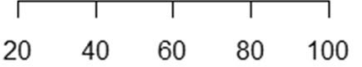

\section{B}

Study

Al-Azzawi et al. 2018 Amundsen et al. 2005

Andretta et al. 2014

Arlen et al. 2011

Bertapelle et al. 2008

Carone et al. 1999

Chaabane et al. 2011

Chartier-Kastler et al. 2000

Chen et al. 2015

Daniels et al. 2010

Denzinger et al. 2012

Engeler et al. 2015

Hohenfellner et al. 1998

Hohenfellner et al. 2001

Ishigooka et al. 1998

Lavano 2004

Lombardi 2014

Marinkovic et al. 2010

Minardi et al. 2012

Peters et al. 2013

Sharifiaghdas 2019

Sievert et al. 2010

Wallace et al. 2007

Wöllner et al. 2016

Random effects model

Heterogeneity: $I^{2}=51 \%, \tau^{2}=0.4598, p=0.04$
Events Total $\quad \begin{gathered}\text { Events per } 100 \\ \text { observations }\end{gathered}$

Events $\quad 95 \%-\mathrm{Cl}$

$75.00 \quad[19.41 ; 99.37]$

$39.13 \quad[19.71 ; 61.46]$

70.59 [44.04; 89.69]

70.00 [45.72; 88.11]

91.67 [61.52; 99.79]

83.33 [51.59; 97.91]

83.78 [67.99; 93.81]

100.00 [66.37; 100.00]

$92.31 \quad[63.97 ; 99.81]$

70.83 [48.91; 87.38]

$100.00[59.04 ; 100.00]$

87.50 [61.65; 98.45]

90.91 [58.72; 99.77]

58.33 [27.67; 84.83]

75.00 [19.41; 99.37]

83.33 [35.88; 99.58]

88.24 [72.55; 96.70]

$100.00[73.54 ; 100.00]$

86.67 [59.54; 98.34]

90.48 [80.41; 96.42]

$100.00[39.76 ; 100.00]$

80.00 [44.39; 97.48]

89.29 [71.77; 97.73]

85.71 [69.74; 95.19]

84.20 [77.82; 89.01]

Fig. 4 a Meta-analysis of the test success rate of SNM (forest plot including studies with $\geq 4$ patients). $\mathbf{b}$ Meta-analysis of the SNM success rate of the permanent implant (forest plot including studies with $\geq 4$ patients; per-protocol analysis)

outcomes remained stable for a follow-up of up to 61 months $[44,60]$. The results from this large meta-analysis can be interpreted as real- world data providing significant real-world evidence for such a heterogeneous group of patients [61]. 
Test success rates varied greatly depending on the type of neurologic condition. The highest test success rates were achieved in patients with back surgery, MS, and pelvic surgery (84.1\%, $76.6 \%$, and $77.8 \%$, respectively), suggesting a higher likelihood for preservation of nerve plasticity or reversibility.

Test success rates in patients with neurogenic non-obstructive urinary retention were slightly lower than for patients with $\mathrm{nDO}(52 \%$ versus $61 \%)$, consistent with the data reported by Kessler et al. (56\% versus 61\%) [12]. Test success rates for combined lower urinary tract symptoms (nDO and voiding difficulties) were 69\% and thereby almost identical to those reported by Hennessey et al. for detrusor hyperactivity with impaired contractility (70\%) [62].

Table 4 Adverse events with permanent SNM

\begin{tabular}{|c|c|c|c|}
\hline $\begin{array}{l}\text { Adverse } \\
\text { event }\end{array}$ & $\begin{array}{l}\text { No. of } \\
\text { patients with } \\
\text { adverse } \\
\text { event/total } \\
\text { no. of } \\
\text { permanently } \\
\text { implanted } \\
\text { patients }\end{array}$ & $\begin{array}{l}\text { Percentage } \\
\text { of adverse } \\
\text { events }\end{array}$ & $\begin{array}{l}\text { No. of } \\
\text { studies } \\
\text { reporting } \\
\text { type of } \\
\text { AE }\end{array}$ \\
\hline Infection & $18 / 494$ & $3.6 \%$ & 8 \\
\hline $\begin{array}{l}\text { Pain at } \\
\text { implant }\end{array}$ & $16 / 494$ & $3.2 \%$ & 8 \\
\hline $\begin{array}{l}\text { Adverse } \\
\text { stimulation }\end{array}$ & $10 / 494$ & $2.0 \%$ & 5 \\
\hline $\begin{array}{l}\text { Lead } \\
\text { migration }\end{array}$ & $16 / 494$ & $3.2 \%$ & 7 \\
\hline Lead breakage & $6 / 494$ & $1.2 \%$ & 4 \\
\hline $\begin{array}{l}\text { Hardware } \\
\text { issues }\end{array}$ & $14 / 494$ & $2.8 \%$ & 6 \\
\hline $\begin{array}{l}\text { Adverse } \\
\text { change in } \\
\text { bowel } \\
\text { function }\end{array}$ & $2 / 494$ & $0.4 \%$ & 1 \\
\hline $\begin{array}{l}\text { Loss of } \\
\text { effectiveness }\end{array}$ & $23 / 494$ & $4.7 \%$ & 9 \\
\hline Other & $9 / 494$ & $1.8 \%$ & 6 \\
\hline
\end{tabular}

Chaabane et al. concluded that the type of nLUTD (retention or DO) has no impact on the test success rate [34]. Three studies reported an improvement of detrusor-sphincter dyssynergia (DSD) with SNM [31, 34, 44].

Patients with MS are an interesting population for SNM because of the high prevalence of nLUTD or fecal incontinence $(75 \%$ and $29 \%$, respectively) [15]. SNM seems to be an attractive option because it can be evaluated for all those conditions. However, its usage has previously been limited by the lack of full-body MRI compatibility. Since new full-body MRI-safe devices have become recently commercially available for $1.5 \mathrm{~T}$ and $3 \mathrm{~T}$ (Axonics, Irvine, CA and Medtronic, Minneapolis, MN), more patients with MS could gain access to this minimally invasive, reversible treatment. New SNM technologies with smaller rechargeable devices (Axonics r-SNM, $5.5 \mathrm{~cm}^{3}$; Medtronic InterStim Micro, $2.8 \mathrm{~cm}^{3}$ ) with an expected battery life of up to 15 years [14] offer significant advantages for patients with a need for high stimulation amplitudes, which is not rare among the neurological patient population. In their case series, Minardi et al. observed a mean amplitude of $3.6 \mathrm{~V}$ (range 2.3-5.8 V) for patients with MS [44] resulting in a mean battery life of approximately 5 years. For example, in a standard, mostly non-neurogenic SNM patient population, effective modulation can nowadays be achieved by a mean amplitude of $0.95 \mathrm{~V}$ with optimized lead placement [63]. In addition, small buttock-placed rechargeable SNM devices are expected to be advantageous in wheelchairbound (neurological) patients [64].

OnabotulinumtoxinA with a level of evidence $1 \mathrm{a}$ is the standard treatment for refractory $\mathrm{nDO}$ due to MS or SCI according to current guidelines [13]. Nevertheless, the discontinuation (ca. 40\%) is significant and can be up to $86 \%$ in patients with MS [11]. Therefore, alternative treatment options are urgently needed, despite the momentary weaker evidence for SNM.

There are legitimate concerns for using SNM in patients with a progressive neurological condition. Chaabane et al. reported that three out of seven patients with MS (43\%) failed SNM because of disease progression [34]. On the 
other hand, in their prospective cohort study, Peters et al. suggested that neurological patients with a progressive condition as well as those with a nonprogressive condition benefited from SNM. No significant differences in terms of revisions, explants, complications, or reprogramming have been observed between the two groups [45]. In fact, another prospective study showed that SNM can be effective in patients with progressive MS [40]. Nevertheless, it is common practice to consider SNM only in patients with disease stability over the last 6-12 months. New medications for MS may also prevent a relapse or progression of symptoms and help to prolong the benefit of SNM [40].

SNM has also demonstrated durable longterm results in patients with incomplete SCI [43]. These patients and other neurological patients may suffer from nDO. In these cases, the protection of the upper urinary tract is of utmost importance in order to prevent renal failure [8]. Hohenfellner et al. reported a reduction in maximum detrusor pressure $\left(\right.$ maxP $_{\text {det }}$ ) by SNM (from 48 to $24 \mathrm{cmH}_{2} \mathrm{O}$ ) [54] and can range from $12.1 \%$ to $60.0 \%[49,65,66]$. Although the exact mechanism of action of SNM has not been fully elucidated, it is generally thought that SNM plays a key role in modulating pathological afferent signals at spinal and supraspinal levels [67]. On the basis of these considerations the impact of SNM on reduction of $\mathrm{P}_{\mathrm{det}}$ may be limited. Regular urodynamic examinations are therefore recommended in patients with significant nDO. However, this applies also for pharmacological treatments. It is noteworthy that apart from the pressure level, the frequency of DO contractions and the duration of elevated detrusor pressures can also gradually harm the upper urinary tract [8]. The reduction of detrusor pressures by SNM can be comparable with other treatment modalities [68, 69], although such indirect comparisons have methodological weaknesses. Furthermore, $\mathrm{nDO}$ often requires concomitant therapies because of the complex nature of the condition.

In the context of the absence of a reliable predictor, a prior test SNM, even over a prolonged period of time, has a high prognostic value for the therapeutic effect of chronic SNM.
Although complete SCI is commonly considered as a general contraindication for SNM, Sievert et al. showed that early bilateral SNM, while still in spinal shock phase, prevents nDO by potentially involving hypogastric-sympathetic nerves [31]. However, until these promising early results for SNM in complete SCI are confirmed, this indication remains investigational. The potential significance of an earlier application of SNM has also been suggested in other studies [70].

In two small retrospective case series on patients with PD, success rates for permanent SNM varied greatly with follow-up periods of up to 18 months and longer $(8 / 8$ [100\%] and $7 / 13$ [54\%]) [71, 72]. Test success rates for patients with PD seem to be lower than for idiopathic LUTD [34]. Joussain et al. suggested that SNM could be a good alternative for patients with PD and $\mathrm{nDO}$ because of the risk of urinary retention with onabotulinumtoxinA [73].

\section{Limitations}

When comparing test success rates for various conditions, confounding factors must be taken into account, such as variations in techniques (basic test with a temporary wire versus advanced test with the permanent tined lead or unilateral versus bilateral modulation). Permanent implants and implant techniques have evolved significantly over the last 25 years $[2,6,58,74]$.

Further limitations of some of the included studies and therefore this meta-analysis are related to heterogeneous patient populations, insufficient disease classification, substantial between-study heterogeneity, and variations in terms of outcome parameter (success rates). Nevertheless, several studies have demonstrated that a symptom improvement of at least 50\% during the test phase correlates favorably with patient-reported outcomes (such as a high patient satisfaction or quality of life improvement) in up to $94 \%$ of patients during the chronic SNM phase [21, 44, 45, 48, 49, 57]. Moreover, a small number of explants can also be interpreted as a clinically meaningful patient satisfaction [48, 75]. 
Further limitations include significant risk of bias, small sample sizes in some studies, retrospective case series with potential reporting bias, or in part poor reporting and publication quality. Publication bias seems to be of lesser importance, since only one study included in the meta-analysis for permanent SNM reported unrestricted industry funding (Table $2 S$ in the supplementary material). It is noteworthy that randomized controlled studies of SNM in nLUTD are lacking [76].

In 2016 a framework for the product life cycle of medical devices has been developed [77]. The IDEAL concept (Idea, Development, Exploration, Assessment, Long-term study) aims at enabling patient access to devices with adequate clinical evidence but without excessive delay or resource use [77]. SNM in patients with nLUTD could be categorized according to IDEAL stage 3 or 4 , since prospective studies are available, randomized trials are underway [76], and long-term data exists $[44,60]$. Cooperative registries could provide further insights into patient selection for this very heterogeneous group of patients. It is noteworthy that SNM in patients with nLUTD is neither a new surgical technique nor does it relate to an entirely new indication, albeit bladder behavior may be very different between neurogenic and non-neurogenic conditions.

Last but not least the differentiation between neurogenic and non-neurogenic etiologies is not always straightforward, as in the cases of SCI, MS, PD, or cerebral vascular disease. Classification of patients with previous pelvic or back surgeries or concomitant diabetes is not without ambiguity. Moreover, the term "nonneurogenic" may be inappropriate with regards to the following well-known, clinically observed paradox: "in SNM modulating the nervous system of patients referred to as 'idiopathic', and of obtaining favorable results in a number of different, and often contradictory, clinical situations is a paradox." [78].

\section{CONCLUSIONS}

This systematic literature review showed that there is growing evidence for the effectiveness of SNM in neurological patients. Although this indication has been investigated since the early days of SNM, it was not a realistic option in routine clinical practice, because full-body MRIapproved devices were lacking. Consequently, SNM was either not offered or devices had to be even explanted. With the recent approval of full-body MRI-certified devices a new era of SNM has begun. This meta-analysis supports not only the benefits of permanent SNM for various neurogenic conditions but also high overall success rates. The overall chance to receive a chronic implant with long-term benefit is approximately 55\% (intention-to-treat analysis).

Finally, the evidence of this meta-analysis in an overall large heterogenous neurological patient population should ignite further prospective trials with more vigorous study designs (including validated patient-reported outcomes such as quality of life) that focus on specific subgroups. Moreover, a central registry on SNM in patients with nLUTD would be helpful to shed more light onto clinical outcomes of such a heterogeneous patient population before definitive conclusions can be drawn.

\section{ACKNOWLEDGEMENTS}

The authors would like to thank PHMR for performing the statistical analysis.

Funding. Funding for the conduct of this meta-analysis was provided by Medtronic International Trading Sarl, Switzerland. The Rapid Service and Open Access Fees were as well funded by Medtronic.

Authorship. All named authors meet the International Committee of Medical Journal Editors (ICMJE) criteria for authorship for this article, take responsibility for the integrity of the work as a whole, and have given their approval for this version to be published.

Authorship Contributions. Arndt van Ophoven and Karl-Dietrich Sievert designed the study. All authors contributed to the content of 
the manuscript. Arndt van Ophoven, Karl-Dietrich Sievert, Stefan Engelberg and Helen Lilley drafted the manuscript. The acquisition of data has been performed by van Ophoven, Sievert, Lilley and Engelberg. The statistical analysis was done by PHMR. All authors approved the final version of the manuscript.

Disclosures. Arndt van Ophoven has consulting agreements with Allergan/Abbvie, Astellas, Axonics and Medtronic. Karl-Dietrich Sievert is a co-founder and shareholder of StimWave and has consulting agreements with StimWave and Promedon. He receives paid consulting fees from Medtronic as honoraria for invited speaker. Stefan Engelberg is a Medtronic employee (Clinical Consultant). Helen Lilley has been an employee of PHMR, which received payments from Medtronic in the conduct of this study. Currently Helen Lilley works as a medical writer for MTech Access, UK.

Compliance with Ethics Guidelines. This article is based on previously conducted studies and does not contain any new studies with human participants or animals performed by any of the authors.

Data Availability. The database analyzed during the current study is available from the corresponding author on reasonable request.

Open Access. This article is licensed under a Creative Commons Attribution-NonCommercial 4.0 International License, which permits any non-commercial use, sharing, adaptation, distribution and reproduction in any medium or format, as long as you give appropriate credit to the original author(s) and the source, provide a link to the Creative Commons licence, and indicate if changes were made. The images or other third party material in this article are included in the article's Creative Commons licence, unless indicated otherwise in a credit line to the material. If material is not included in the article's Creative Commons licence and your intended use is not permitted by statutory regulation or exceeds the permitted use, you will need to obtain permission directly from the copyright holder. To view a copy of this licence, visit http://creativecommons.org/licenses/by$\mathrm{nc} / 4.0 /$.

\section{REFERENCES}

1. Liberman D, Ehlert MJ, Siegel SW. Sacral neuromodulation in urological practice. Urology. 2017;99:14-22.

2. Schmidt RA, Jonas U, Oleson KA, et al. Sacral nerve stimulation for treatment of refractory urinary urge incontinence. Sacral Nerve Stimulation Study Group. J Urol. 1999;162(2):352-7.

3. Hassouna MM, Siegel SW, Nÿeholt AA, et al. Sacral neuromodulation in the treatment of urgency-frequency symptoms: a multicenter study on efficacy and safety. J Urol. 2000;163(6):1849-54.

4. Jonas U, Fowler CJ, Chancellor MB, et al. Efficacy of sacral nerve stimulation for urinary retention: results 18 months after implantation. J Urol. 2001;165(1):15-9.

5. Gajewski JB, Hassouna MM, Corcos J, Gray GJ, Tu LM, Dwyer N. The history of sacral neuromodulation in Canada. Can Urol Assoc J. 2020;14(4):87-90.

6. Tanagho EA, Schmidt RA, Orvis BR. Neural stimulation for control of voiding dysfunction: a preliminary report in 22 patients with serious neuropathic voiding disorders. J Urol. 1989;142(2 Pt 1):340-5.

7. Agrawal S, Agrawal RR, Wood HM. Establishing a multidisciplinary approach to the management of neurologic disease affecting the urinary tract. Urol Clin North Am. 2017;44(3):377-89.

8. Mehnert U, Chartier-Kastler E, de Wachter S, van Kerrebroeck P, van Koeveringe G. The management of urine storage dysfunction in the neurological patient. SN Compr Clin Med. 2018;1(3):160-82.

9. Tijnagel MJ, Scheepe JR, Blok BF. Real life persistence rate with antimuscarinic treatment in patients with idiopathic or neurogenic overactive bladder: a prospective cohort study with solifenacin. BMC Urol. 2017;17(1):30. https://doi.org/10. 1186/s12894-017-0216-4.

10. Patel DP, Herrick JS, Stoffel JT, et al. Reasons for cessation of clean intermittent catheterization after spinal cord injury: results from the Neurogenic Bladder Research Group spinal cord injury registry. Neurourol Urodyn. 2020;39(1):211-9. 
11. Leitner L, Guggenbühl-Roy S, Knüpfer SC, et al. More than 15 years of experience with intradetrusor onabotulinumtoxinA injections for treating refractory neurogenic detrusor overactivity: lessons to be learned. Eur Urol. 2016;70(3):522-8.

12. Kessler TM, La Framboise D, Trelle S, et al. Sacral neuromodulation for neurogenic lower urinary tract dysfunction: systematic review and metaanalysis. Eur Urol. 2010;58(6):865-74.

13. EAU Guidelines 2020. https://uroweb.org/ guideline/neurourology/\#3. Accessed 25 Aug 2020.

14. De Wachter S, Knowles CH, Elterman DS, et al. New technologies and applications in sacral neuromodulation: an update. Adv Ther. 2020;37(2):637-43.

15. Hennessey A, Robertson NP, Swingler R, Compston DA. Urinary, faecal and sexual dysfunction in patients with multiple sclerosis. J Neurol. 1999;246(11):1027-32.

16. Traboulsee A, Simon JH, Stone L, et al. Revised recommendations of the consortium of MS centers task force for a standardized MRI protocol and clinical guidelines for the diagnosis and follow-up of multiple sclerosis. AJNR Am J Neuroradiol. 2016;37(3):394-401.

17. Kaunzner UW, Gauthier SA. MRI in the assessment and monitoring of multiple sclerosis: an update on best practice. Ther Adv Neurol Disord. 2017;10(6): 247-61.

18. Bodley R. Imaging in chronic spinal cord injury-indications and benefits. Eur J Radiol. 2002;42(2):135-53.

19. Pagliacci MC, Franceschini M, Di Clemente B, Agosti M, Spizzichino L, GISEM. A multicentre follow-up of clinical aspects of traumatic spinal cord injury. Spinal Cord. 2007;45(6):404-10.

20. Moher D, Shamseer L, Clarke M, et al. Preferred reporting items for systematic review and metaanalysis protocols (PRISMA-P) 2015 statement. Syst Rev. 2015;1(4):1.

21. Marinkovic SP, Gillen LM. Sacral neuromodulation for multiple sclerosis patients with urinary retention and clean intermittent catheterization. Int Urogynecol J. 2010;21:223-8.

22. Howick J, Chalmers I, Glasziou P, et al. The Oxford 2011 levels of evidence. 2011. https://www.cebm. ox.ac.uk/resources/levels-of-evidence/ocebmlevels-ofevidence. Accessed 25 Aug 2020.

23. Sterne JA, Hernán MA, Reeves BC, et al. ROBINS-I: a tool for assessing risk of bias in non-randomised studies of interventions. BMJ. 2016;12(355):i4919. https://doi.org/10.1136/bmj.i4919.

24. McGuinness LA, Higgins JPT. Risk-of-bias VISualization (robvis): an R package and Shiny web app for visualizing risk-of-bias assessments. Res Syn Meth. 2020. https://doi.org/10.1002/jrsm.1411].

25. R Core Team. R: A language and environment for statistical computing [Internet]. Vienna, Austria: R Foundation for Statistical Computing; 2019. https://www.r-project.org/.

26. Carone R, Bertapelle P, Zanollo A, et al. Sacral neuromodulation in neurogenic lower urinary tract dysfunctions: results of a multicenter study group. Urodinamica. 1999;9:177-82.

27. Minardi D, Muzzonigro G. Lower urinary tract and bowel disorders and multiple sclerosis: role of sacral neuromodulation: a preliminary report. Neuromodulation. 2005;8:176-81.

28. Dudding TC, Hollingshead JR, Nicholls RJ, Vaizey CJ. Sacral nerve stimulation for faecal incontinence: patient selection, service provision and operative technique. Colorectal Dis. 2011;13(8):e187-95.

29. Hohenfellner M, Humke J, Hampel C, et al. Chronic sacral neuromodulation for treatment of neurogenic bladder dysfunction: long-term results with unilateral implants. Urology. 2001;58:887-92.

30. Schurch B, Reilly I, Reitz A, Curt A. Electrophysiological recordings during the peripheral nerve evaluation (PNE) test in complete spinal cord injury patients. World J Urol. 2003;20:319-22.

31. Sievert K-D, Amend B, Gakis G, et al. Early sacral neuromodulation prevents urinary incontinence after complete spinal cord injury. Ann Neurol. 2010;67:74-84.

32. Al-Azzawi IS, Al-Tamimi MAJ. The first Iraqi experience in sacral neuromodulation for patients with lower urinary tract dysfunction. Arab J Urol. 2018;16:391-6.

33. Arlen AM, Powell CR, Kreder KJ. Sacral neuromodulation for refractory urge incontinence is less effective following spinal surgery. Sci World J. 2011;11:142-6.

34. Chaabane W, Guillotreau J, Castel-lacanal E, et al. Sacral neuromodulation for treating neurogenic bladder dysfunction: clinical and urodynamic study. Neurourol Urodyn. 2011;30:547-50.

35. Chartier-Kastler EJ, Ruud Bosch JL, Perrigot M, Chancellor MB, Richard F, Denys P. Long-term results of sacral nerve stimulation (S3) for the treatment of neurogenic refractory urge 
incontinence related to detrusor hyperreflexia. J Urol. 2000;164:1476-80.

36. Chen G, Liao L. Sacral neuromodulation for neurogenic bladder and bowel dysfunction with multiple symptoms secondary to spinal cord disease. Spinal Cord. 2015;53:204-8.

37. Daniels DH, Powell CR, Braasch MR, Kreder KJ. Sacral neuromodulation in diabetic patients: success and complications in the treatment of voiding dysfunction. Neurourol Urodyn. 2010;29(4): 578-81.

38. Denzinger S, Nowrotek A, Weingart $P$, et al. Does sacral neuromodulation lead to relevant reduction in the need for intermittent catheterization? A single-center experience on patients with chronic urinary retention. Neuromodulation Technol Neural Interface. 2012;15:586-91.

39. Dobberfuhl AD, Mahal A, Dallas KB, Choi KM, Comiter CV, Elliott CS. Statewide success of staged sacral neuromodulation for the treatment of urinary complaints in California (2005-2011). Female Pelvic Med Reconstr Surg. 2018. https://doi.org/10. 1097/SPV.0000000000000605.

40. Engeler DS, Meyer D, Abt D, Müller S, Schmid H-P. Sacral neuromodulation for the treatment of neurogenic lower urinary tract dysfunction caused by multiple sclerosis: a single-centre prospective series. BMC Urol. 2015;15:105. https://doi.org/10.1186/ s12894-015-0102-X.

41. Lansen-Koch SMP, Govaert B, Oerlemans D, et al. Sacral nerve modulation for defaecation and micturition disorders in patients with spina bifida. Colorectal Dis. 2012;14:508-14.

42. Lavano A, Volpentesta G, Aloisi M, Veltri C, Piragine G, Signorelli CD. Use of chronic sacral nerve stimulation in neurological voiding disorders. J Neurosurg Sci. 2004;48:157-9.

43. Lombardi G, Musco S, Celso M, Del Corso F, Del Popolo G. Sacral neuromodulation for neurogenic non-obstructive urinary retention in incomplete spinal cord patients: a ten-year follow-up singlecentre experience. Spinal Cord. 2014;52:241-5.

44. Minardi D, Muzzonigro G. Sacral neuromodulation in patients with multiple sclerosis. World J Urol. 2012;30:123-8.

45. Peters KM, Kandagatla P, Killinger KA, Wolfert C, Boura JA. Clinical outcomes of sacral neuromodulation in patients with neurologic conditions. Urology. 2013;81:738-44.

46. Seif C, Eckermann J, Bross S, Portillo FJM, Jünemann K-P, Braun P-M. Findings with bilateral sacral neurostimulation: sixty-two PNE-tests in patients with neurogenic and idiopathic bladder dysfunctions. Neuromodulation. 2004;7:141-5.

47. Spinelli M, Giardiello G, Gerber M, Arduini A, van den Hombergh U, Malaguti S. New sacral neuromodulation lead for percutaneous implantation using local anesthesia: description and first experience. J Urol. 2003;170:1905-7.

48. Wallace PA, Lane FL, Noblett KL. Sacral nerve neuromodulation in patients with underlying neurologic disease. Am J Obstet Gynecol. 2007;197:96.e196.e5.

49. Wöllner J, Krebs J, Pannek J. Sacral neuromodulation in patients with neurogenic lower urinary tract dysfunction. Spinal Cord. 2016;54:137-40.

50. Zhang P, Wang JY, Zhang Y, et al. Results of sacral neuromodulation therapy for urinary voiding dysfunction: five-year experience of a retrospective, multicenter study in China. Neuromodulation. 2019;22(6):730-7.

51. Amundsen CL, Romero AA, Jamison MG, Webster GD. Sacral neuromodulation for intractable urge incontinence: are there factors associated with cure? Urology. 2005;66:746-50.

52. Andretta E, Simeone C, Ostardo E, Pastorello M, Zuliani C. Usefulness of sacral nerve modulation in a series of multiple sclerosis patients with bladder dysfunction. J Neurol Sci. 2014;347:257-61.

53. Bertapelle P, Bodo G, Carone R. Detrusor acontractility in urinary retention: detrusor contractility test as exclusion criteria for sacral neurostimulation. J Urol. 2008;180(1):215-6.

54. Hohenfellner M, Schultz-Lampel D, Dahms S, Matzel K, Thüroff JW. Bilateral chronic sacral neuromodulation for treatment of lower urinary tract dysfunction. J Urol. 1998;160(3 Pt 1):821-4.

55. Ishigooka M, Suzuki Y, Hashimoto T, Sasagawa I, Nakada T, Handa Y. A new technique for sacral nerve stimulation: a percutaneous method for urinary incontinence caused by spinal cord injury. Br J Urol. 1998;81(2):315-8.

56. Sharifiaghdas F. Sacral neuromodulation in congenital lumbo-sacral and traumatic spinal cord defects with neurogenic lower urinary tract symptoms: a single-center experience in children and adolescents. World J Urol. 2019;37(12):2775-83.

57. Siegel S, Noblett K, Mangel J, et al. Five-year followup results of a prospective, multicenter study of patients with overactive bladder treated with sacral neuromodulation. J Urol. 2018;199(1):229-36. 
58. Noblett K, Siegel S, Mangel J, et al. Results of a prospective, multicenter study evaluating quality of life, safety, and efficacy of sacral neuromodulation at twelve months in subjects with symptoms of overactive bladder. Neurourol Urodyn. 2016;35(2): 246-51.

59. Bartley JM, Killinger KA, Boura J, et al. The impact of prior back surgery on neuromodulation outcomes: a review of over 500 patients. Neurourol Urodyn. 2017;36(6):1535-42.

60. Lombardi G, Del Popolo G. Clinical outcome of sacral neuromodulation in incomplete spinal cord injured patients suffering from neurogenic lower urinary tract symptoms. Spinal Cord. 2009;47: 486-91.

61. Katkade VB, Sanders KN, Zou KH. Real world data: an opportunity to supplement existing evidence for the use of long-established medicines in health care decision making. J Multidiscip Healthc. 2018;11: 295-304. https://doi.org/10.2147/JMDH.S160029.

62. Hennessey DB, Hoag N, Gani J. Sacral neuromodulation for detrusor hyperactivity with impaired contractility. Neurourol Urodyn. 2017;36(8): 2117-22.

63. Lehur PA, Sørensen M, Dudding TC, et al. Programming algorithms for sacral neuromodulation: clinical practice and evidence-recommendations for day-to-day practice. Neuromodulation. 2020. https://doi.org/10.1111/ner.13117.

64. Manjunath A, Keeter MK, Koloms K, Kielb SJ. Abdominal versus standard placement of the sacral nerve stimulator implantable pulse generator. Urology. 2019;127:49-52.

65. Groen J, Ruud Bosch JL, van Mastrigt R. Sacral neuromodulation in women with idiopathic detrusor overactivity incontinence: decreased overactivity but unchanged bladder contraction strength and urethral resistance during voiding. J Urol. 2006;175(3 Pt 1):1005-9.

66. Groenendijk PM, Lycklama à Nyeholt AA, Heesakkers JP, et al. Urodynamic evaluation of sacral neuromodulation for urge urinary incontinence. BJU Int. 2008;101(3):325-9.

67. De Wachter S, Vaganee D, Kessler TM. Sacral neuromodulation: mechanism of action. Eur Urol Focus. 2020. https://doi.org/10.1016/j.euf.2019.11. 018.
68. Krebs J, Pannek J. Effects of solifenacin in patients with neurogenic detrusor overactivity as a result of spinal cord lesion. Spinal Cord. 2013;51(4):306-9.

69. Chen YC, Kuo HC. The therapeutic effects of repeated detrusor injections between 200 or 300 units of onabotulinumtoxinA in chronic spinal cord injured patients. Neurourol Urodyn. 2014;33(1):129-34.

70. Hassouna MM, Elkelini MS. Early versus late treatment of voiding dysfunction with pelvic neuromodulation. Can Urol Assoc J. 2007;1(2):106-10. https://doi.org/10.5489/cuaj.52.

71. Greenberg D, Sohlberg E, Zhang C, Comiter CV, Enemchukwu E. Sacral neuromodulation in Parkinson's disease patients with neurogenic bladder. Neurourol Urodyn. 2019;38(S1):S204.

72. Peyronnet B, Biardeau X, Cornu JN, et al. Sacral neuromodulation in patients with Parkinson's disease: a multicenter study. Neurourol Urodyn. 2019;38(S1):S126.

73. Joussain C, Phé V, Even A, Chartier-Kastler E, Denys $P$. Intradetrusor injection of botulinum toxin $A$ and sacral neuromodulation for neurogenic detrusor overactivity. Eur J Phys Rehabil Med. 2017;53(6): 991-7.

74. Matzel KE, Chartier-Kastler E, Knowles $\mathrm{CH}$, et al. Sacral neuromodulation: standardized electrode placement technique. Neuromodulation. 2017;20(8):816-24.

75. Groen J, Blok BF, Bosch JL. Sacral neuromodulation as treatment for refractory idiopathic urge urinary incontinence: 5-year results of a longitudinal study in 60 women. J Urol. 2011;186(3):954-9.

76. Knüpfer SC, Liechti MD, Mordasini L, et al. Protocol for a randomized, placebo-controlled, double-blind clinical trial investigating sacral neuromodulation for neurogenic lower urinary tract dysfunction. BMC Urol. 2014;14:65.

77. Sedrakyan A, Campbell B, Merino JG, Kuntz R, Hirst A, McCulloch P. IDEAL-D: a rational framework for evaluating and regulating the use of medical devices. BMJ. 2016;9(353):i2372. https://doi.org/10. 1136/bmj.i2372.

78. Spinelli M. The future of sacral nerve stimulation. Pelviperineology. 2007;26:17-18. http://cms. galenos.com.tr/Uploads/Article_37222/ Pelviperineology-26-17-En.pdf. 